\title{
A participação dos negros escravos na guerra do Paraguai
}

ANDRÉ AMARAL DE TORAL

A $S$ DENÚNCIAS DE QUE O exército brasileiro ao lutar na guerra (1864-1870) era formado por escravos não são novas. Ao contrário, têm pelo menos cento e vinte anos. Seus primeiros autores foram os redatores dos jornais paraguaios da época. Tratavam de menosprezar o exército brasileiro com base no duvidoso argumento de que, por ser formados por negros, deveria ser de qualidade inferior.

Mais recentemente, diversos autores tentaram ressuscitar o argumento de que o exército brasileiro, era formado por negros escravos alistados compulsoriamente.

Soldados negros, ex-escravos ou não, lutaram em pelo menos três dos quatro exércitos dos países envolvidos. Os exércitos paraguaio, brasileiro e uruguaio tinham batalhóes formados exclusivamente por negros. Como exemplos temos o Corpo dos Zuavos da Bahia e o batalhão uruguaio Florida. Escravos propriamente ditos, engajados como soldados, lutaram comprovadamente nos exércitos paraguaio e brasileiro.

Para se avaliar corretamente a participação dos negros escravos na guerra é preciso, primeiramente, esquecer ou suspender a questão das nacionalidades envolvidas. Com efeito, se os negros lutaram sob pelo menos três das quatro bandeiras presentes no conflito, o foco da análise deve ser posto sob a situação dos escravos e de seus descendentes nesses exércitos e não sobre suas nacionalidades.

Não repito aqui o erro dos ideólogos lopiztas, que consideravam o exército brasileiro - soldados e oficiais - formado indistintamente por macacos; e nem o dos detratores do Paraguai, que consideravam seu exército formado por caboclos, termo depreciativo que no Brasil designa índios e seus descendentes mais ou menos aculturados, e seu povo formado por descendentes dosguarani, uma vaga referência etnográfica. Negros e índios teriam sido, por essas análises baseadas em simplificaçôes raciais, as maiores vítimas da guerra.

Para além dessas versões ideologizantes, procurarei esclarecer a convocação do negro, ex-escravo, aos exércitos paraguaio e brasileiro, bem como sua participação na guerra. 


\section{Como matar a los negros}

A frase dita pelo presidente paraguaio Francisco Solano López depois de receber na barriga o golpe de lança do cabo de ordens do coronel Joca Tavares, seu xará Francisco Lacerda - matem a esos diablos de macacos! -, é reveladora da idéia que seu governo queria fazer dos brasileiros no país.

$\mathrm{Na}$ época da guerra (1864-1870), no Paraguai, o negro era, antes de tudo, o inimigo. $\mathrm{O}$ exército brasileiro era o exército macacuno, e seus líderes, segundo a propaganda lopizta, macacos que pretendiam escravizar o povo paraguaio, conduzindo-os da liberdade à escravidão.

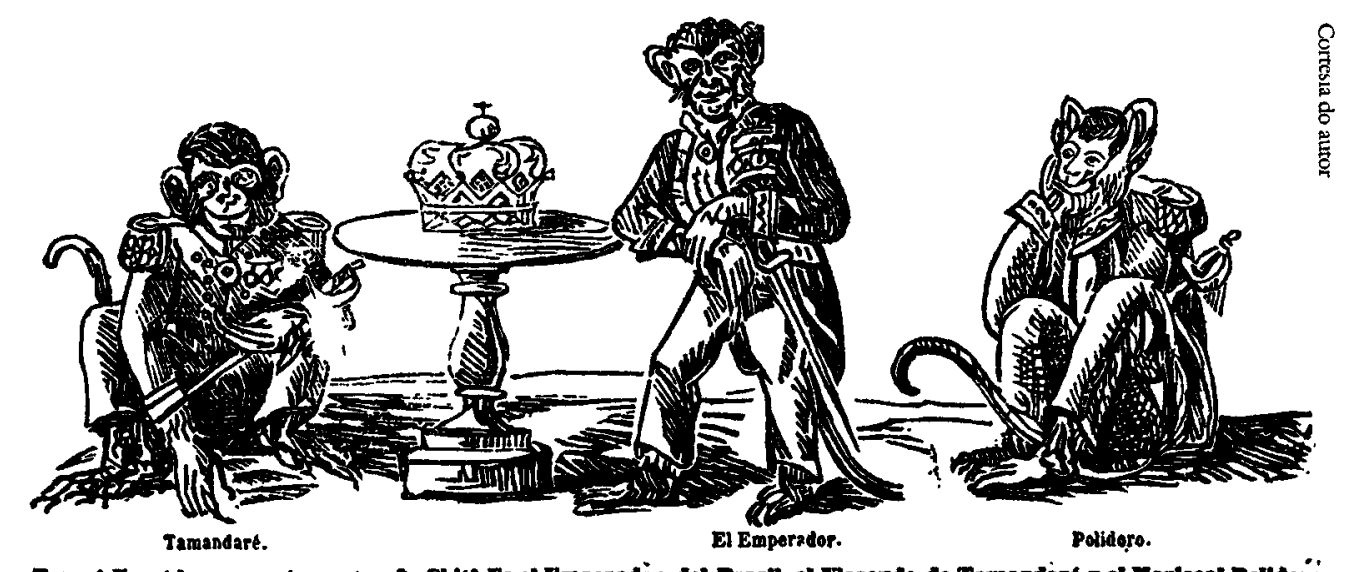

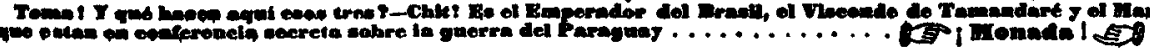

Trếs macacos: o Imperador, Tamandaré e Polidoro no jormal El Centinela de 1867

O imperador é definido como um gran macaco representado sempre com uma longa cauda, Caxias um descomunal sapo preto que se locomovia montado numa tartaruga. O Cabichui, jornal do exército paraguaio, define o soldado brasileiro: "La palabra guaraní camba se aplica a los negros, y más generica y propriamente al esclavo. Hablar de un brasilero es, pues, hablar de un camba bajo el punto de vista de su color y de su condicion de esclavo, y aun mas propriamente de uncamba para representar la ruindad, la pequeñez, la miseria, el amilanamiento de esa raza despreciable que hasta es una afrenta para la especie humana" (Museo del Barro 1984, Cabichuí, n. 8, 1).

$\mathrm{Na}$ imprensa oficial, através do Cabichuíe do El Centinela eram freqüentes chamadas como: "Así se cazam los negros"; "Fuego a los negros"; "Como matar a los negros"; "Ejercito macacuno jugando Carnaval”; "Látigo con los negros" etc.

Com base na propaganda poder-se-ia pensar que no Paraguai da época não 
existiriam negros nem escravos. Por conseguinte não existiriam, também, negros escravos ou ex-escravos no exército paraguaio.

A realidade era diferente. A escravidão não havia sido abolida do Paraguai. O que havia era uma lei do ventre livre promulgada em 1842 por Carlos Lopes, pai de Francisco Solano López. Os libertos da República, os que nasciam de janeiro de 1843 em diante, deveriam, no entanto, trabalhar para seus senhores, patronos, os homens até a idade de 25 anos e as mulheres até os 24 . Era uma liberdade bastante relativa, portanto.

O recrutamento sistemático de escravos no Paraguai inicia-se em setembro de 1865, apenas um ano depois do início da guerra, para preencher as baixas de feridos e de epidemias que assolaram o exército. Destacamentos formados por exescravos vindos do interior foram vistos em Assunção em meados de 1966 (Laurent-Cochelet, apud Rivarola, 1988:132). Este seria, no entanto, o segundo contingente importante de homens de cor-negros ou mulatos- incorporados ao exército. O primeiro foi integrado à Divisão que fez a invasão do Mato Grosso e da Argentina, em 1864 e 1865.

Em uma foto de oito prisioneiros paraguaios capturados em 1866 por Flores aparece um negro, com o gorro de couro dos soldados de infantaria pintado com as cores da República paraguaia.

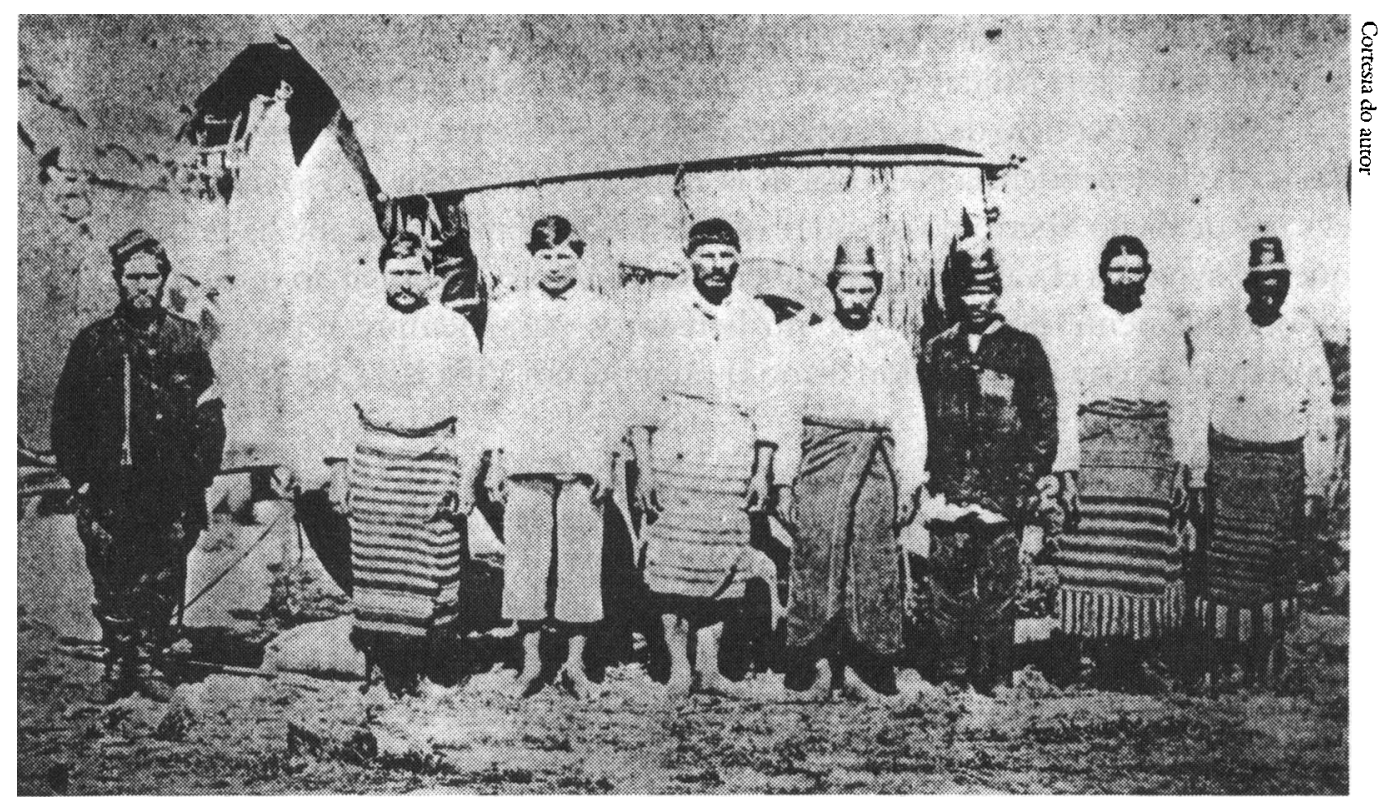

Grupo de prisioneiros paraguaios capturados pelos aliados em 1866 
Em setembro de 1866 outro grupo de escravos é alistado para preencher as graves baixas sofridas pelo exército paraguaio nas batalhas de Estero Bellaco e Tuyuti ( 2 e 24 de maio de 1866). Estes seriam os últimos no território paraguaio (Rivarola, 1988:132-133). Pode-se dizer, de maneira trágica, que a guerra acabou, de fato, com a escravidão no país. Sob o ponto de vista legal, a escravidão no Paraguai foi abolida pelo Conde D'Eu, "baseado em sua própria autoridade" (Schulz, 1994:71), então comandante das forças brasileiras, em setembro de 1869, depois da invasão de Assunção e da virtual, ainda que incompleta, vitória militar dos aliados.

As autoridades paraguaias, que convocaram os proprietários de escravos para doações voluntárias, ofereciam uma indenização, mas ninguém se permitia reclamá-la (Rivarola, 1988:133). No Arquivo Geral de Assunção ainda se conservam aproximadamente uma dezena dessas cartas de doação de escravos para a guerra. Os textos parecem seguir um padrão, tendo sido lavrados na mesma ocasião e pela mesma mão. Sem dúvida alguma, os proprietários foram pressionados à doação. Vejamos uma dessas cartas:

“Sello Tercero [do governo de López] año de 1866

!Viva la República del Paraguay!

Digo yo la infrascrita Gregoria Larrosa natural de la República y vicina de Villa Rica que otorgo entera libertad al liberto de la República Celestino de quince años de edad que lo hube por compra a Da. Iginia Leyta y lo presento ante el señor Comandante Militar de esta Vila para que sea enrolado como hombre libre y destinado al Servicio de las Armas en la presente Guerra con los enemigos de la libertad e Independencia Nacional de la República sin exigir precio ninguno por el valor de dicho liberto no obstante que el Señor Comandante me ha prevenido que me avonaria el valor de dicho liberto en el Tesoro Nacional, lo que renuncio espontaneamente por mi y por mi herederos para siempre y para perpetua constancia de esta manumisión firmo la presente em Villa Rica a 4 de noviembre de 1866.

A ruego de Na. Gregoria Lamosa por decir no saber firmar. Gregorio Vasquez" (Archivo General, seción histórica, v. 349).

O exame desse documento mostra que o comércio de escravos continuou mesmo depois da lei de ventre livre. Mostra também que os libertos da República não deviam unicamente trabalho aos seus senhores. Estes, e o Estado paraguaio, dispunham de suas pessoas. Era um regime de escravidão plena, no qual o Estado praticava um confisco. Chama a atenção, nesse caso concreto, a pouca idade do escravo Celestino, quinze anos apenas, destinado à guerra. 
Não só a população escrava é recrutada na sua totalidade. Até setembro de 1866 já se recrutara toda a população masculina entre dez e 60 anos (Masterman, apud Rivarola, 1988). A partir daí, o envolvimento de toda a população masculina para a guerra é total e, em meados de 1867 , praticamente já não existem exceções para o recrutamento. Velhos, inválidos e doentes são convocados. Crianças de sete anos são convocadas, ainda nesse ano, para o serviço militar (Rivarola, 1988:133). O extermínio da população masculina paraguaia é compreendido quando se pensa que a guerra e as convocaçóes só terminariam três anos depois, em 1870.

O alistamento de escravos deve ser entendido, portanto, na perspectiva de um país com população de 400 mil pessoas (Brun, 1989:18) que enfrentava uma invasão de países com populações muito mais numerosas que a sua.

O paraguaio, ante o recrutamento forçado, tem na deserção a única saída. As primeiras iniciam-se já em 1865, na coluna que invadiu o Brasil. Sua continuidade e o aumento da criminalidade no interior do país fará o governo López adotar duras medidas contra os desertores, seus companheiros e famílias. Essas medidas ficaram tristemente famosas. O caso do mulato desertor Bernardo Pelaes, gradualmente moído numa prensa de tabaco é apenas um entre muitos (LaurentCochelet, apud Rivarola, 1988:138).

\section{Lutar é para os pobres: \\ o escravo no exército brasileiro}

A população brasileira em 1850, 14 anos antes da guerra, era de aproximadamente dez milhóes de pessoas, das quais uma quarta parte era constituída de escravos (Gorender, 1978:319). Os insuficientes efetivos do exército brasileiros foram reforçados, para a guerra, pelos contingentes da polícia e da Guarda Nacional das províncias do império. Criou-se em janeiro de 1865, além disso, os Corpos de Voluntários da Pátria para canalizar o movimento patriótico que, num primeiro momento, levou muitas pessoas a se alistarem para lutar contra a invasão paraguaia do Rio Grande do Sul e de Mato Grosso (Fragoso, 1934:35-37).

Como a campanha se anunciasse longa e o entusiasmo popular arrefecesse, os presidentes das províncias recebiam cotas de voluntários que deveriam encaminhar ao cenário da guerra. Ainda em 1865 iniciou-se o recrutamento forçado para formação dos Corpos de Voluntários da Pátria; e o termovoluntários tornou-se uma piada (Schulz, 1994:59).

Os chefes políticos locais e a oficialidade da Guarda Nacional, que era uma milícia à mando dos oligarquias rurais, tentavam forçar o alistamento de seus oponentes causando sérios conflitos nas províncias. 
Os cidadãos do império dispunham de diversas formas de se esquivarem da convocaçāo. Os mais aquinhoados, utilizavam-se de doaçōes de recursos, equipamentos, escravos e empregados à Guarda Nacional e aos Corpos de Voluntários para lutarem em seu lugar; os que podiam menos, faziam oferecimento de familiares, ou seja, alistavam seus parentes, filhos, sobrinhos, agregados etc.

Aos despossuídos não restava outro recurso para escapar ao alistamento que a fuga para o mato. A população do corte e das províncias rebelavam-se contra as autoridades recrutadoras, os delegados de polícia e seus prepostos, que "iam caçar o caboclo no Amazonas e no Pará, o tabaréu nordestino na caatinga, o matuto na sua tapera, o caiçara no litoral, enfim brancos, mulatos e negros que, depois de reunidos e contados, eram despachados em magotes" (Queiroz Duarte, apud Salles, 1990:102). A questão do recrutamento militar compulsório, aliada à disputa do ministério liberal de Zacarias com o conservador Caxias pela disputa da condução da guerra, forçaram a queda do primeiro em 1868, criando grave crise política e a volta dos conservadores.

A compra de substitutos, ou seja, a compra de escravos para lutarem em nome de seus proprietários, tornou-se prática corrente. Sociedades patrióticas, conventos e o governo encarregavam-se, além disso, da compra de escravos para lutarem na guerra. $O$ império prometia alforria para os que se apresentassem para a guerra, fazendo vista grossa para os fugidos.

O próprio imperador deu o exemplo, libertando todos os escravos das fazendas nacionais (Schulz, 1994:60) para lutarem na guerra. Em dezembro de 1866 o Imperador escrevia ao seu ministro da guerra: "Forças e mais forças a Caxias, apresse a medida de compra de escravos e todos os que possam aumentar o nosso Exército" (apud Lyra; 1977:241).

Não existem números certos sobre a porcentagem de escravos alistados no exército imperial. Salles (1990:103), que dedicou um livro ao assunto, cita algumas estimativas. Segundo o general Queiroz Duarte, que trabalhou os números dentro de uma ótica que visava a valorizar os alistamentos voluntários, os exescravos, libertos, seriam apenas 8.489 pessoas em meio ao contingente mobilizado para a guerra, que perfazia um total de 123.150 soldados. Ou seja, $6,9 \%$ de escravos do total de soldados do exército.

Robert Conrad, por sua vez, estima em 20 mil o total de escravos, incluindo-se as mulheres dos soldados; que conseguiram a liberdade com a guerra. Um "Mapa dos Libertos que têm assentado praça desde o começo da guerra", elaborado pelo Ministério da Guerra aponta, até abril de 1868, um total de 3.897 escravos cedidos por conventos, substitutos da Casa Imperial, por conta da nafão, por conta do governo etc., o que representava $5,5 \%$ do total do exército (apud Salles, 1990: 64-65). 
Tais dados, apesar de precários e insuficientes, demonstram que o exército brasileiro dificilmente poderia ser compreendido como um exército de escravos, como afirma Chiavenatto (1983:27).

Machado de Assis, em seu romance Iaiá Garcia escrito no final da década de 70, mostra as condiçóes em que um jovem bem-posto socialmente se apresenta ao conflito em 1866. A mãe de um recalcitrante voluntário diz, a certa altura: "podemos arranjar-lhe um posto de tenente ou alferes" no Corpo de Voluntários da Pátria (1951:16). O que se esconde por trás de suas palavras é meio óbvio: uma família de posses compra divisas e postos no exército.

O general Dionísio Cerqueira, que alistou-se voluntariamente, deu outro exemplo na mesma linha: "um primo carnal, o major da Guarda Nacional João Evangelista de Castro Tanajura, moço rico, organizou formoso corpo de gente escolhida no sertão, vestiu-o, alimentou-o e transportou-o até a capital onde foi aquartelado para seguir para o sul". Esse mesmo corpo foi subtraído ao comando do referido oficial, em função de politica partidária, o que o levou à morte por febre cerebral causada por desgosto (Cerqueira, 1980:56).

Torna-se claro que os limites da cidadania efetiva do império iguala os escravos e despossuídos como material humano disponível para a guerra. A Guarda Nacional, apesar da inspiração liberal do modelo francês, terminou a serviço de oligarquias, alistando compulsoriamente qualquer um, desde que pobre ou adversário político. Os Voluntários da Pátria, por seu lado, dada a ausência de entusiasmo popular depois da fase inicial da guerra, também receberam em suas fileiras escravos e substitutos de toda sorte.

A questão aqui parece ser menos racial e mais de exclusão social. Além dos limites estreitos da cidadania todos são compreendidos como voluntários, bons para a guerra. Os mais aquinhoados têm mais condiçôes de escaparem; os mais pobres recorrem ao exílio dos matos. O que menos dispóe de meios de resistência é exatamente o escravo, que troca a enxada pelo mosquetão, deixa de obedecer ao capataz e entrega sua vida ao senhor oficial.

A situação era tal que o escritor Joaquim Manoel de Macedo, líder da facção avançada do Partido Liberal, afirmou na época: "os brasileiros náo se alistavam voluntariamente por acreditarem que só os pobres lutavam" (Schulz, 1994:61).

Além de convocados de forma compulsória, escravos ou seus descendentes libertos, sofriam com a discriminação racial dentro do próprio exército. $\mathrm{O}$ contingente sulista (Rio Grande do Sul e Bahia foram as províncias que mais contribuíram com homens para a guerra) recebia mal os homens de cor do Norte e do Nordeste. Um dito popular entre os sulistas no exército em operaçôes era: "Mandai, 
Mãe de Deus, mais alguns dias de Minuano para acabar com tudo que é baiano" (Cerqueira, 1980:72).

Dentro do próprio exército em campanha reproduziam-se aspectos da sociedade que o engendrou. Soldados pobres trabalhavam para os oficiais como criados. A Ordem do Dia para 24 de maio de 1866, dia da batalha de Tuiuti, deixava bem claro que todos os integrantes dos batalhões deveriam estar a postos, "mesmo os bagageiros e camaradas dos senhores oficiais" (Cerqueira, 1980:155).

Muitos anos depois da guerra, um antigo oficial - Dionísio Cerqueira -, filho de família rica do interior da Bahia, encontrou-se com seu ex-camarada (criado). Este se perfilou, tirou o chapéu e abraçando sua perna, pois o oficial estava a cavalo, disse, comovido: "Seu ajudante... meu senhor... (Cerqueira, 1980:340).

\section{Lutando a guerra dos outros}

O Império do Brasil que foi à guerra era, como é até hoje, o maior e mais populoso Estado da América do Sul. Suas exportaçóes de café, açúcar e algodão eram muito maiores que as de todos os outros países envolvidos somados. Sua população escrava excedia em muito toda a população paraguaia. Em 1862 assumiu um ministério liberal depois da hegemonia conservadora que vinha desde 1848. O Brasil, no cenário internacional e junto à opinião pública nacional, havia sido humilhado na Questão Christie. Somando uma espinhosa discussão sobre a renovação do Tratado Comercial e a repressão ao tráfico negreiro, o Império rompeu relaçóes com a Inglaterra em 1862. Internamente, as coisas também não iam bem: em 1864 ocorreu grave crise financeira, que acarretou falta de crédito e de dinheiro na praça.

A invasão brasileira do Uruguai, em defesa dos estancieiros gaúchos, e a posterior agressão paraguaia, em solidariedade aos blancos uruguaios, invadindo o Rio Grande do Sul e o Mato Grosso, foram oportunidades para o ministério Zacarias mostrar-se competente defensor da enxovalhada honra nacional e dos interesses das elites brasileiras no exterior (Doratioto, 1994).

López, por seu lado, planejava a redistribuição de poder na bacia do Prata. Através de uma esperada união de interesses com as separatistas províncias argentinas de Entre Rios e Corrientes, e com os blancos depostos pelos brasileiros no Uruguai, sonhava em romper o isolamento de seu país através do porto de Montevideo e contrapor-se ás políticas de Buenos Aires e do Rio de Janeiro.

A Argentina havia sido recentemente unificada sob os unitários de Buenos 
Aires com a derrota dos federalistas agrupados sob a Confederação Argentina. Com o término do longo processo conhecido como luta dos estados argentinos (1850-62), o governo Mitre via com muita preocupação López formar um exército poderoso e aliar-se às províncias secessionistas. Para a Argentina porteña interessava a destruição de López e de seu exército, condição imprescindível para selar a unidade nacional (Brun, 1989:192).

O prolongamento da guerra trouxe conseqüências conhecidas. Ao reatamento de relações da Inglaterra com o Brasil em 1865, seguiu-se o financiamento da guerra por créditos conseguidos na praça daquele país, o enriquecimento de fornecedores argentinos e a destruição do Paraguai e de significativa parte de sua população. Todas as questóes fronteiriças pendentes foram resolvidas com a derrota das reivindicações paraguaias por direito de conquista, e o país destruído, $o$ que também servia aos interesses porteños.

No Brasil, um império que baseava sua economia na exploração da mãode-obra escrava, a cidadania excluía boa parte de sua população. A situação no Paraguai também era, nesse sentido, excludente. Sua sociedade baseava-se em comunidades de self-sustaining members e latifúndios, muitos deles estatais, encimados por um governo fortemente autoritário, no qual o Estado retinha a propriedade da terra e participava do processo de produçăo, garantindo as condições do isolamento do país (Bandeira, 1985:159-160). A República paraguaia estava longe de ser uma República. O Congresso, convocado para aprovar Francisco Solano López como presidente, não se reunia há muitos anos; e durante a guerra não se reuniu uma única vez. A vontade do presidente e a de sua família impunham-se sobre o Judiciário e o Legislativo. Um sistema de delação, espionagem e repressão policial implacável desencorajava críticas e veleidades de participação nas decisóes governamentais, até das elites criollas.

A sorte dos escravos que lutaram na guerra do Paraguai se liga mais à questionável cidadania no Brasil e no Paraguai do que à questão de discriminação racial. $\mathrm{O}$ alistamento compulsório atingia igualmente o escravo, a população paraguaia e os pobres brasileiros. Os direitos individuais não existiam nem na monarquia constitucional escravocrata brasileira, nem na pretensa República paraguaia. Buscar algo de específico à condição negra como característica principal na formação de exércitos e, portanto, das vítimas da guerra corresponde a uma demanda contemporânea sobre um contexto histórico que não responde a essas indagaçóes.

Referências bibliográficas

BANDEIRA, Moniz. O expansionismo brasileiro. O papel do Brasil na bacia do Prata da colonização ao Império. Rio de Janeiro, Philobiblion, 1985. 
BRUN, Diego Abente. La guerra de la Triple Alianza: tres modelos explicativos. Asunción, Revista Paraguaya de Sociología, v. 26, n. 74, ene./abr. 1989.

CERQUEIRA, Dionísio. Reminiscências da campanha do Paraguai, 1865-1870. Rio de Janeiro, Biblioteca do Exército Editora, 1980.

CHIAVENATTO, Júlio José. Os Voluntários da Pátria e outros mitos. São Paulo, Editora Global, 1983.

DORATIOTO, Francisco F. Monteoliveira. Há 130 anos da Tríplice Aliança. Brasília, Revista Brasileira de Politica Intemacional, v. 37, n. 2, 1994.

EL CENTINELA. Colección del semanario de los paraguayos en la guerra de la Triple Alianza 1867. Buenos Aires, Fondo Editorial Paraquariae, 1964.

FRAGOSO, Augusto Tasso (General de Divisão). História da guerra entre a Tríplice Aliança e o Paraguai, 5 v. Rio de Janeiro, Imprensa do Estado Maior do Exército, 1934.

GORENDER, Jacob. O escravismo colonial. São Paulo, Ática, 1978.

LYRA, Heitor. História de D. Pedro II. 1825-1891, 3 v. Ascensão, 1. v. São Paulo, Edusp/Itatiaia, 1977.

MACHADO DE ASSIS, Joaquim Maria. Yayá Garcia. São Paulo, Clube do Livro, 1951.

MUSEO DEL BARRO. Cabichui. Periodico de la guerra de la triple alianza (edição facsimilar). Asunción, Edición Museo del Barro, 1984. 1985.

. La Guerra del 70. Una visión fotografica. Asunción, Edición Museo del Barro,

RIVAROLA, Milda. La polemica francesa sobre la guerra grande. Eliseo Reclus: la guerra del Paraguay/Laurent-Cochelet: correspondencia consular. Asunción, Editorial Historica, 1988.

SALLES, Ricardo. Guerra do Paraguai: escravidāo e cidadania na formação do exército. Rio de Janeiro, Paz e Terra, 1990.

SCHULZ, John. O exército na política. Origens da intervenção militar, 1850-1894. São Paulo, Editora da Universidade de São Paulo, 1994.

André Amaral de Toral é doutorando no Departamento de História Social da Faculdade de Filosofia, Letras e Ciências Humanas da USP e mestre em Antropologia Social pelo Museu Nacional (UFRJ). 